\title{
Age-Related Differences and Heritability of the Perisylvian Language Networks
}

\author{
Sanja Budisavljevic, ${ }^{1,2,6}$ Flavio Dell'Acqua, ${ }^{1,2}$ Frühling V. Rijsdijk, ${ }^{3}$ Fergus Kane, ${ }^{4}{ }^{\circledR}$ Marco Picchioni, ${ }^{4}$ Philip McGuire, ${ }^{4}$ \\ Timothea Toulopoulou, ${ }^{4,5,7,8}$ Anna Georgiades, ${ }^{5}$ Sridevi Kalidindi, ${ }^{5}$ Eugenia Kravariti, ${ }^{5}$ Robin M. Murray, ${ }^{5}$ \\ Declan G. Murphy, ${ }^{1}$ Michael C. Craig, ${ }^{1,2,9 *}$ and Marco Catani ${ }^{1,2 *}$ \\ ${ }^{1}$ Department of Forensic and Neurodevelopmental Sciences, ${ }^{2}$ Natbrainlab, Centre for Neuroimaging Sciences, ${ }^{3}$ Social, Genetic and Developmental \\ Psychiatry Research Centre, ${ }^{4}$ Department of Psychological Medicine, and ${ }^{5}$ Department of Psychosis Studies, Institute of Psychiatry, Psychology and \\ Neuroscience, King's College London, London SE5 8AF, United Kingdom, ${ }^{6}$ NeMo Laboratory, Department of General Psychology, University of Padova, \\ 35131 Padova. Italy, ${ }^{7}$ Department of Psychology and ${ }^{8}$ State Key Laboratory of Brain and Cognitive Sciences, The University of Hong Kong, Hong Kong, and \\ ${ }^{9}$ National Autism Unit, South London and Maudsley NHS Foundation Trust, United Kingdom
}

Acquisition of language skills depends on the progressive maturation of specialized brain networks that are usually lateralized in adult population. However, how genetic and environmental factors relate to the age-related differences in lateralization of these language pathways is still not known. We recruited 101 healthy right-handed subjects aged 9-40 years to investigate age-related differences in the anatomy of perisylvian language pathways and 86 adult twins ( 52 monozygotic and 34 dizygotic) to understand how heritability factors influence language anatomy. Diffusion tractography was used to dissect and extract indirect volume measures from the three segments of the arcuate fasciculus connecting Wernicke's to Broca's region (i.e., long segment), Broca's to Geschwind's region (i.e., anterior segment), and Wernicke's to Geschwind's region (i.e., posterior segment). We found that the long and anterior arcuate segments are lateralized before adolescence and their lateralization remains stable throughout adolescence and early adulthood. Conversely, the posterior segment shows right lateralization in childhood but becomes progressively bilateral during adolescence, driven by a reduction in volume in the right hemisphere. Analysis of the twin sample showed that genetic and shared environmental factors influence the anatomy of those segments that lateralize earlier, whereas specific environmental effects drive the variability in the volume of the posterior segment that continues to change in adolescence and adulthood. Our results suggest that the age-related differences in the lateralization of the language perisylvian pathways are related to the relative contribution of genetic and environmental effects specific to each segment.

Key words: arcuate fasciculus; diffusion tensor tractography; heritability; language; network asymmetry; lateralization

Significance Statement

Our study shows that, by early childhood, frontotemporal (long segment) and frontoparietal (anterior segment) connections of the arcuate fasciculus are left and right lateralized, respectively, and remain lateralized throughout adolescence and early adulthood. In contrast, temporoparietal (posterior segment) connections are right lateralized in childhood, but become progressively bilateral during adolescence. Preliminary twin analysis suggested that lateralization of the arcuate fasciculus is a heterogeneous process that depends on the interplay between genetic and environment factors specific to each segment. Tracts that exhibit higher age effects later in life (i.e., posterior segment) appear to be influenced more by specific environmental factors.

\section{Introduction}

The perisylvian language network has a pivotal role in language and incorporates temporal, parietal, and frontal brain regions

Received March 28, 2014; revised May 21, 2015; accepted July 11, 2015.

Author contributions: S.B., F.K., M.P., P.M., T.T., R.M.M., D.G.M., and M.C. designed research; S.B., F.K., A.G., S.K., and E.K. performed research; S.B., F.D., and F.V.R. analyzed data; S.B., M.C.C., and M.C. wrote the paper.

This study was funded by the Medical Research Council United Kingdom (Grant G0400061) as an Autism Imaging Multicentre Study with support from the National Institute for Health Research (NIHR) Biomedical Research Centre at South London and Maudsley National Health Service (NHS) Foundation Trust, King's College London, the Sackler Institute for Translational Neurodevelopment. Additional funding was provided by the European Autism Interven- connected by the arcuate fasciculus (Catani et al., 2002, 2003; Catani and Mesulam, 2008; Forkel et al., 2014). Until recently, the anatomy of white matter pathways, including the arcuate fasciculus, could only be studied using invasive postmortem examination and tracing methods (Schmahmann and Pandya, 2006).

tions-A Multicentre Study for Developing New Medications (EU-AIMS), which received support from the Innovative Medicines Initiative Joint Undertaking (Grant 115300), including financial contributions from the European Union Seventh Framework Programme (Grant FP7/2007-2013), the European Federation of Pharmaceutical Industries and Associations companies in kind, Autism Speaks, National Alliance for Research in Schizophrenia and Affective Disorders, The Stanley Foundation, Schizophrenia Research Trust, and the Psychiatry Research Trust. M.C. is the 
With the advent of diffusion tensor imaging (DTI)-MRI, the anatomy of this perisylvian pathway was found to be more complex than previously thought (Catani et al., 2005, 2012b). In addition to the "direct" long segment between inferior frontal (i.e., Broca's region) and posterior temporal cortex (Wernicke's region), the presence of an "indirect" pathway was observed, which includes a posterior segment connecting Wernicke's to the inferior parietal lobule (i.e., Geschwind's region) and an anterior segment connecting Broca's and Gescwhind's regions.

The lateralization of the arcuate fasciculus is probably a dynamic process that begins very early in life (Dubois et al., 2009) and continues throughout adolescence and early adulthood (Paus et al., 1999; Eluvathingal et al., 2007; Lebel and Beaulieu, 2009). In young adults, the lateralization of the three segments is heterogeneous, with left volume asymmetry reported for the long segment, right asymmetry for the anterior segment, and symmetrical hemispheric distribution for the posterior segment (Catani et al., 2007; Thiebaut de Schotten et al., 2011; López-Barroso et al., 2013). This heterogeneity might be linked to observed agerelated differences in white matter microstructure during childhood and adolescence (Eluvathingal et al., 2007; Lebel and Beaulieu, 2009). However, there are no studies that investigated volumetric lateralization of the three segments from childhood to adulthood. Therefore, at the first stage of the current study, we completed an analysis of the anatomy and asymmetry of the volume of the three segments of the arcuate fasciculus in a large group of 101 healthy subjects across an age range spanning from 9 to 40 years. We hypothesized that there would be age-related differences in the anatomy of the three arcuate segments, reflecting their different functional specialization.

Factors that influence age-related differences probably involve a complex interaction between genetic and environmental effects. Previously, in vivo studies have reported a significant genetic contribution to the variability of left language cortices (Thompson et al., 2001; Joshi et al., 2011) and white matter microstructure of the arcuate fasciculus in children (Brouwer et al., 2010) and healthy adults (Chiang et al., 2009; Kochunov et al., 2010). To understand how hereditary mechanisms may relate to hemispheric bias for processing language, that is, how age-related differences in lateralization patterns of different arcuate segments might be influenced by genetic and environmental factors, we devised a second analysis using a classical twin study design. We compared the DTI-MRI of 26 monozygotic (MZ) and 17 dizygotic (DZ) adult twin pairs and tested the hypothesis that there would be differences in heritability patterns between the segments, possibly linked to anatomical age-related variability.

\section{Materials and Methods}

Subjects. In the first study, we analyzed 101 healthy right-handed volunteers aged 9-40 years. Handedness was assessed using the Edinburgh

recipient of a Welcome Trust Investigator Award (Grant 103759/Z/14/Z). The views expressed are those of the authors and are not necessarily those of the NHS, the NIHR, or the Department of Health. We thank the NatBrainLab (www.natbrainlab.com) for helpful comments on the manuscript.

The authors declare no competing financial interests.

*M.C.C. and M.C. contributed equally to this work.

This article is freely available online through the J Neurosci Author Open Choice option.

Correspondence should be addressed to Sanja Budisavljevic or Marco Catani, Natbrainlab, Section of Brain Maturation P050, Department of Forensic and Neurodevelopmental Sciences, King's College London, Institute of Psychiatry, Psychology and Neuroscience, De Crespigny Park, London SE5 8AF, UK, E-mail: sanja.budisavljevic@gmail.com or m.catani@iop.kcl.ac.uk.

DOI:10.1523/JNEUROSCI.1255-14.2015

Copyright $\odot 2015$ Budisavljevic et al.

This is an Open Access article distributed under the terms of the Creative Commons Attribution License Creative Commons Attribution 4.0 International, which permits unrestricted use, distribution and reproduction in any medium provided that the original work is properly attributed.
Handedness Inventory (Oldfield, 1971). The second study included 86 healthy right-handed adult twin subjects, $26 \mathrm{MZ}$ and $17 \mathrm{DZ}$ twin pairs, recruited from a volunteer twin register at the Institute of Psychiatry, London, and by national media advertisements. Mean age for MZ twins was 35.5 years (range, 21-56), and 42.5 years (range, 20-62) for DZ twins. All DZ twin pairs included for this study were same-sex pairs. Opposite-sex pairs were excluded to avoid inflation of heritability estimates due to an overall lower DZ correlation (Stromswold, 2001). Of the $26 \mathrm{MZ}$ twin pairs, nine pairs were male and 17 female. Of the $17 \mathrm{DZ}$ twin pairs, four pairs were male and 13 female. Other exclusion criteria included a history of neurological disorder or systemic illness with known neurological complications, significant head injury associated with loss of consciousness for $>1 \mathrm{~min}$, and current harmful substance use or dependence (defined as within the last 12 months). Informed written consent was obtained from all the subjects before participating. For the first study dataset, approval was obtained from the Joint Medical Ethical Committee of the Institute of Psychiatry, Kings College London. For the twin dataset, the UK Multicenter Research Ethics Committee granted the ethics approval.

DTI-MRI data acquisition. DTI data were acquired using a Signa 1.5-T LX MRI system (General Electric) with a maximum gradient amplitude of $40 \mathrm{mT} / \mathrm{m}$ and an acquisition sequence fully optimized for DTI-MRI and tractography of white matter as described previously by Jones et al. (2002). Each volume was acquired using a multislice spin echo EPI sequence covering the whole brain and with sections parallel to the anterior-posterior commissure line. Each DTI-MRI volume was acquired from 60 contiguous 2.5 -mm-thick slices with a field of view of $240 \times 240$ $\mathrm{mm}$ and an acquisition matrix size of $96 \times 96$ pixels, giving a voxel size of $2.5 \mathrm{~mm} \times 2.5 \mathrm{~mm} \times 2.5 \mathrm{~mm}$. Echo time was $102 \mathrm{~ms}$. Acquisitions were peripherally gated with an effective repetition time of $15 \mathrm{R}-\mathrm{R}$ intervals. At each location, seven images were acquired without diffusion weighting, together with 64 images with a weighting of $1300 \mathrm{~s} / \mathrm{mm}^{2}$ applied along directions uniformly distributed in space.

Tractography algorithm. Diffusion data were analyzed using ExploreDTI (Leemans et al., 2009). After correction for eddy current distortions and subject motion (Jones et al., 2002), the DTI was estimated using a nonlinear least-squares method and fractional anisotropy (FA) and mean diffusivity (MD) maps were estimated. Whole-brain tractography was performed using a b-spline interpolation of the diffusion tensor field and Euler integration to propagate streamlines following the directions of the principal eigenvector with a step size of $0.5 \mathrm{~mm}$. Tractography was started in all brain voxels with $F A>0.2$. Streamlines were tracked until the FA of the tensor was above an FA threshold of 0.2 or the curvature (i.e., the angle between two consecutive steps) was $<30$ degrees.

Virtual dissections of the perisylvian language networks. Tractography data were visualized using TrackVis (Massachusetts General Hospital) and virtual dissection of white matter bundles performed following previous validated approaches (Catani and Thiebaut de Schotten, 2008). The three segments of the arcuate fasciculus were dissected in each subject in both hemispheres (Fig. 1; Catani et al., 2005, 2007, 2011). Regions of interest were defined on the FA map to encompass the streamlines of the arcuate fasciculus lateral to the corona radiata and medial to the cerebral cortex. A two-ROI approach was used to perform dissection of the three segments of the arcuate fasciculus. To dissect the streamlines of the long segment of the arcuate fasciculus, two spatially separated regions were defined in the frontal and posterior temporal lobe. To dissect the most lateral streamlines of the arcuate fasciculus, which consist of anterior and posterior segments, a third ROI was placed in the inferior parietal lobule. All streamlines passing through inferior frontal region and the inferior parietal lobule were considered to belong to the anterior indirect segment, whereas all streamlines passing through the posterior temporal and the inferior parietal lobule were considered to belong to the posterior indirect segment. To protect against subjective bias, DTI-MRI subjects were mixed in a random order and the operator was blind to zygosity of the twin pairs.

Effects of age study: visitation maps and tract volume measurements. All of the tracts of the first dataset were first converted into binary maps. Binary maps with dimensions equal to that of the DTI-MRI data (i.e., $128 \times 128 \times$ 60 ) were computed by assigning each voxel a value of 1 or 0 depending on 


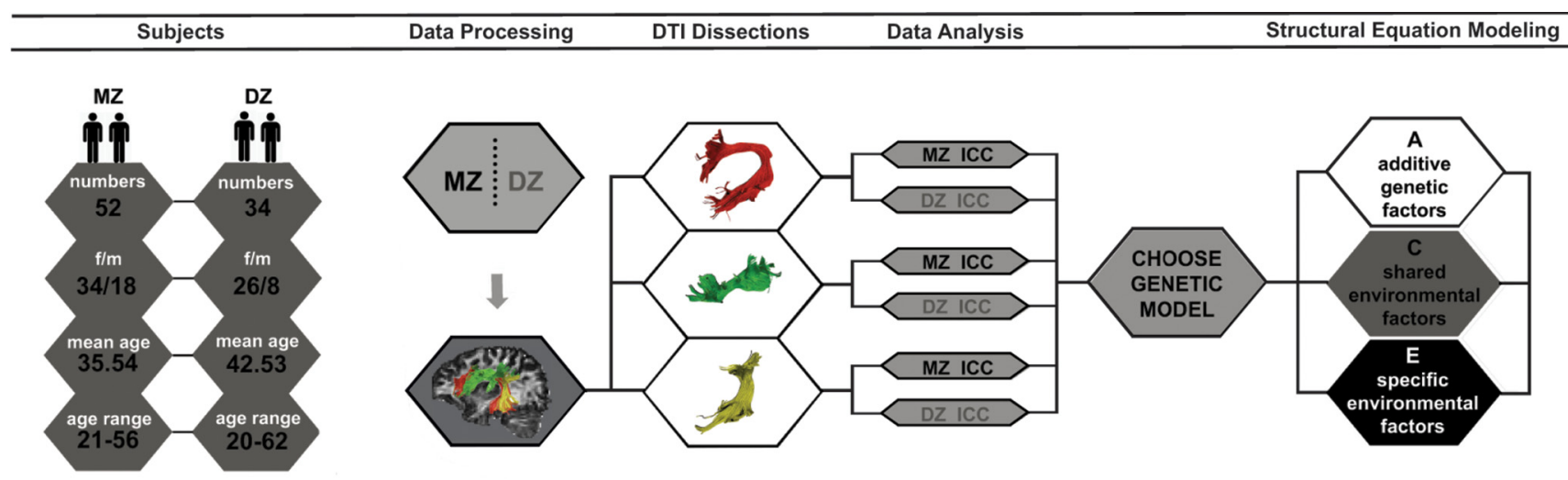

Figure 1. Steps involved in the twin study design.

whether the pixel was intersected by $>1$ streamline or not, respectively. All of the binary masks were normalized to the MNI space (defined by the Montreal Neurological Institute) using the following procedure.

Normalization of all the brains required an adequate template to be estimated. The b0 images from 60 subjects were spatially normalized to the MNI reference space defined by the Echo Planar Imaging (EPI) template supplied as part of the SPM5 software package (Statistical Parametric Mapping; Wellcome Department of Cognitive Neurology, London). The same transformation was applied to the FA map for each subject. FA maps were then averaged to generate a "first guess" template. To refine and improve the quality of this first template, the normalization of the original FA maps was repeated, but this time using the guess as the new template. Afterward, all the FA maps were averaged to obtain the final template and, on this final template, the normalizations of FA maps was repeated. The final transformation was also applied to the binary maps produced for each subject and segment.

The dataset was sorted according to age. A moving average technique with a square window of \pm 5 years was applied and an average visitation map for each year \pm the width of the window was obtained. The visitation map was defined as the average of the binary maps inside of the windows, where the voxel value of 1 is reached when all of the subjects present streamline in that voxel or 0 when no streamlines are present in the given voxel. This technique enabled us to compare the volume difference of each segment of the arcuate fasciculus at different ages.

Statistical analysis. For each segment of the arcuate fasciculus, the number of streamlines and the number of voxels touched by the streamlines (referred to as volume) were calculated as surrogate measurements of the tract volume, together with FA and MD. We confirmed that these quantitative measures were normally distributed and that there was homogeneity of means and variances across the measures (using paired $t$ tests and Levene's test, respectively). Lateralization index (LI) of the number of streamlines and volume was calculated according to the following formula: (volume/number of streamlines, left) - (volume/number of streamlines, right $) /[($ volume/number of streamlines, left $)+$ (volume/number of streamlines, right)]/2. Positive values of the index indicate a greater number of streamlines or volume in the left segment compared with the right, whereas negative values indicate right lateralization. Values around zero indicate a similar number of streamlines or volume between left and right segments. The correlation analysis between age and DTI-extracted measures and their LI was conducted using SPSS version 21.

Figure 1 provides a breakdown of steps used for the analysis of the twin data. A comparison of the intraclass correlation coefficients (ICCs) for each DTI measures in MZ and DZ twins provided an initial, descriptive statistics of the presence of genetic effects. Before quantitative genetic model fitting of the extracted diffusion measures from the arcuate fasciculus connections, age, sex, and handedness were regressed out using SPSS and residuals were standardized for subsequent analysis. Model fitting was performed using the structural equation modeling program OpenMx (Boker et al., 2011) to provide heritability parameter estimates and their confidence intervals (Neale and Maes, 2002). Sources of variance in the DTI-extracted measures were divided into additive genetic effects (A), common environmental effects (C; environmental influences that make the twins more similar), and unique or specific environmental influences that contribute to differences between the twins and also include a possible measurement error (E) (Plomin et al., 2001). Maximum likelihood estimates of $\mathrm{A}, \mathrm{C}$, and $\mathrm{E}$ were obtained (values ranged from 0 to 1 , where $\mathrm{A}+\mathrm{C}+\mathrm{E}=1$ ), $95 \%$ confidence intervals calculated and a series of nested models compared. A full ACE model was compared with the nested AE, CE, and E models (testing the effects of common environmental factors, additive genetic factors, and all familial resemblance, respectively). However, in cases in which effect sizes, sample sizes, or trait prevalence are low, statistical power for univariate twin analyses can become an issue (Neale et al., 1994) and full ACE model estimates are reported. We did not specifically model familial factors, but we analyzed E-only models to test for familial influences that refer to a significant combined effect of A + C. Estimates were considered significant if the reported maximum likelihood $95 \%$ confidence intervals did not contain zero.

\section{Results}

Effects of age on the lateralization of the arcuate volumes

A correlation analysis between age and LIs for the number of streamlines of the three segments showed significant positive correlation for the posterior segment $(r=0.355 ; p<0.001)$, which indicates a progressive decrease of right lateralization with age. There was no correlation between age and lateralization of the long $(r=0.091 ; p=0.34)$ or anterior segment $(r=-0.080 ; p=$ 0.53 ). Further analysis of the individual segments showed a statistically significant correlation with age only for the right posterior segment $(r=-0.366 ; p=0.001)$. Correlation for the left posterior segment was not significant $(r=-0.053 ; p>0.05)$. We used Fisher's $r$-to- $z$ transformation and asymptotic $z$ test to test the difference between two dependent correlations with a variable in common. The analysis showed that the correlations between age and posterior segments were significantly different $(z=-2.32, p=0.01)$. There were no significant correlations with age for the number of streamlines of the anterior and long segments bilaterally.

To visualize age-related differences for each age group, we used a visitation maps approach based on a moving average volume technique. Figure 2 shows the differences in volume between left and right arcuate segments according to age. On average, by the age of 10 years, the long segment is significantly larger in the left hemisphere compared with the right $(p<0.001)$, whereas the anterior segment is significantly larger in the right compared with the left hemisphere $(p<0.001)$. Both segments remain lateralized throughout adolescence and early adulthood. At the whole- 
A

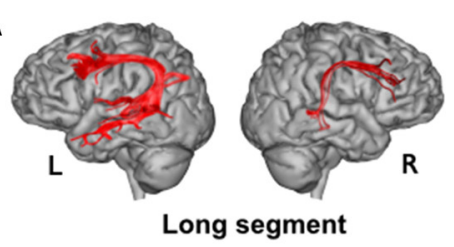

B

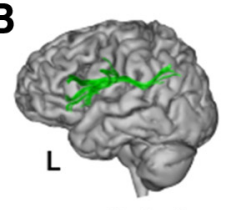

Anterior segment

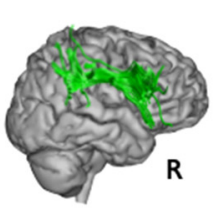

$\mathrm{R}$

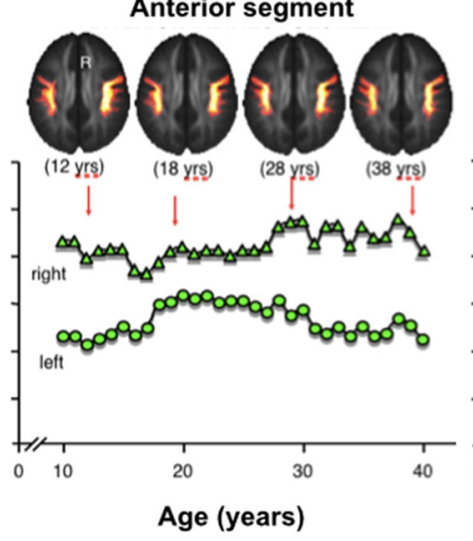

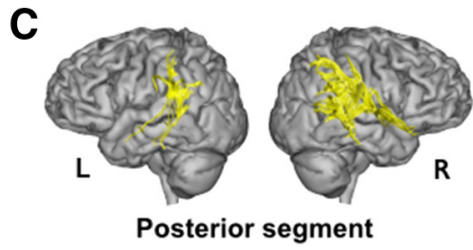

Posterior segment

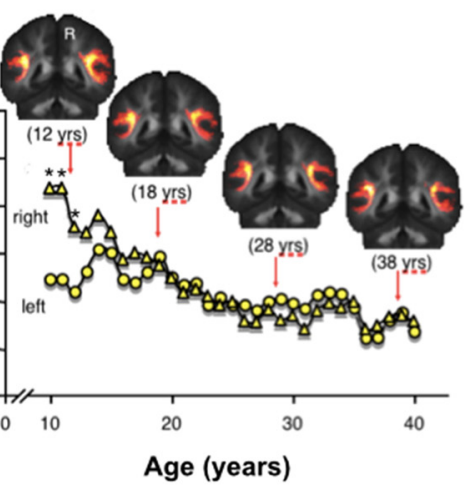

Figure 2. Age-related differences in the volume of the long (frontotemporal), anterior (frontoparietal), and posterior (temporoparietal) segments of the arcuate fasciculus for each hemisphere. Group volumes for each age window (i.e., average volume calculated from subjects with an age range of \pm 5 years around each year) are indicated by triangles for the right segments and circles for the left segments. The axial slices above the graphs show the visitations maps for four representative age groups. $A$, The volume of the long segment is left lateralized in 10 -year-old subjects and remains left lateralized throughout adolescence and early adulthood (differences between left and right volumes are statistically significant at all ages, $p<0.001$ ). $\boldsymbol{B}$, An opposite pattern of lateralization is observed for the anterior indirect segment, which exhibits right lateralization (differences between left and right volumes are statistically significant at all ages, $p<0.001$ ). $\boldsymbol{C}$, The posterior segment shows a statistically significant right lateralization before adolescence (age 9-11). Left and right differences diminish progressively throughout adolescence and adulthood. Asterisks indicate statistically significant differences between left and right $(p<0.001)$.

group level, the average volume of the left long segment ( 543 voxels) is $88.7 \%$ larger than the volume of the long segment in the right hemisphere (61 voxels). Conversely, the average volume of the right anterior segment ( 849 voxels) is $38.4 \%$ larger than the volume of the left anterior segment (523 voxels). The interhemispheric asymmetry of the posterior segment shows a more dynamic pattern, with a greater right volume before adolescence (statistically significant for ages 9, 10, and 11), followed by a progressive bilateral distribution throughout adolescence and early adulthood. By the age of 10, the posterior right segment is $43.8 \%$ larger than its left counterpart ( 872 voxels in the right, and 490 voxels in the left hemisphere); however, by the age of 40 , this difference is only $12.9 \%$ (310 voxels in the right hemisphere; 270 voxels in the left hemisphere). The average values of the LIs $( \pm \mathrm{SD})$ at the whole-group level were $0.95 \pm 95$ for the long segment, $-0.56 \pm 0.65$ for the anterior segment, and $0.04 \pm 0.70$ for the posterior segment.

\section{Effects of age on FA and MD of the arcuate segments}

Correlation analysis between diffusion measures and age revealed a significant negative correlation between age and MD in bilateral posterior (left $r=-0.573, p<0.001$; right $r=-0.602, p<$ 0.001 ) and anterior segments (left, $r=-0.562, p<0.001$; right, $r=-0.595, p<0.001)$ and left long segment $(r=-0.540, p<$ $0.001)$. No significant correlations between FA and age were observed.

Structural equation modeling of genetic and environmental sources of variance that affect the anatomy of the arcuate segments

Lateralization and age effects

The twin study was performed on older adults (mean age: $38.3 \pm$ 13 years; range, 20-62), in whom the pattern of lateralization for the number of streamlines of the long and anterior segments was similar to the pattern found in the age-related study. We observed significant left lateralization of the long segment (LI: $0.88 \pm 0.66$, $p<0.001)$ and significant right asymmetry of the anterior segment (LI: $-0.67 \pm 0.48, p<0.001)$. Conversely, the posterior segment exhibited significant left lateralization (LI: $0.42 \pm 0.62$, $p<0.001)$. There were no significant correlations with age in the twin sample.

ICCs

The ICC results for the number of streamlines and volume measures extracted from each of the three bilateral segments are shown in Table 1 and correlation plots for the lateralization in Figure 3. Overall, the ICCs for the MZ twins were either higher or similar to those of the DZ twins. This may suggest high genetic or shared environmental effects on the anatomy of the three segments. A representative example of the anatomy of the three arcuate segments in $\mathrm{MZ}$ and DZ twin pairs is shown in Figure 4. Genetic versus environmental effects were analyzed using structural equation modeling.

\section{Structural equation modeling}

Structural equation modeling was used to extract the relative contributions of $\mathrm{A}, \mathrm{C}$, and $\mathrm{E}$ on the variability of the volume and number of streamlines of the perisylvian language tracts (Table 1 ). The same analysis was performed for FA and MD measurements. The width of the confidence intervals was sometimes considerable due to the relatively small sample size of the study compared with standard behavioral quantitative genetics' studies. This led us to observe that, for some measures, $A$ and $C$ were nonsignificant individually, but significant as combined familial effect $(A+C)$. In these instances, they were reported together as a familial effect $(A+C)$ (Wright et al., 2002), where the $(A+C) E$ model represents the fit of the full ACE model.

Specific environmental factors (E) significantly explained the variability in volume and the number of streamlines of the right posterior connections ( $72 \%$ and $61 \%$, respectively). In contrast, fa- 
Table 1. MZ and DZ ICCs with standardized additive genetic (A), common environmental (C), and unique environmental (E) variance components of the full ACE model (and 95\% confidence intervals) given for the number of streamlines (tracts) and volume of the long, anterior, and posterior segments in the left (L) and right (R) hemispheres

\begin{tabular}{|c|c|c|c|c|c|c|c|c|c|c|}
\hline Tract & Variable & ICC-MZ & ICC-DZ & A & C & $\mathrm{E}$ & Best-fit model & DF & $\chi^{2}$ & $p$ \\
\hline \multirow[t]{4}{*}{$\begin{array}{l}\text { Long direct } \\
\text { segment }\end{array}$} & $\begin{array}{l}\text { Lno. of tracts } \\
\text { (95\% Cls) }\end{array}$ & $0.70(0.43-0.85)$ & $0.55(0.12-0.81)$ & $0.40(0-0.83)$ & $0.31(0-0.74)$ & $0.29(0.15-0.54)$ & $(A+C) E$ & 6 & 1.22 & 0.98 \\
\hline & $\begin{array}{l}\text { L volume } \\
\qquad(95 \% \text { Cls) }\end{array}$ & $0.68(0.41-0.84)$ & $0.56(0.13-0.81)$ & $0.15(0-0.77)$ & $0.50(0-0.77)$ & $0.35(0.19-0.58)$ & $(A+C) E$ & 6 & 1.14 & 0.98 \\
\hline & $\begin{array}{l}\text { R no. of tracts } \\
\quad(95 \% \mathrm{Cls})\end{array}$ & $0.69(0.41-0.85)$ & $0.58(0.16-0.82)$ & $0.08(0-0.77)$ & $0.60(0-0.79)$ & $0.32(0.17-0.54)$ & $(A+C) E$ & 6 & 11.24 & 0.08 \\
\hline & $\begin{array}{l}\text { R volume } \\
\qquad(95 \% \mathrm{Cls})\end{array}$ & $0.59(0.24-0.80)$ & $0.49(0-0.79)$ & $0(0-0.71)$ & $0.59(0-0.75)$ & $0.41(0.23-0.65)$ & $(A+C) E$ & 6 & 11.58 & 0.07 \\
\hline \multirow[t]{4}{*}{$\begin{array}{l}\text { Anterior indirect } \\
\text { segment }\end{array}$} & $\begin{array}{l}\text { Lno. of tracts } \\
\quad(95 \% \text { Cls })\end{array}$ & $0.52(0.18-0.75)$ & $0.01(-0.46-0.49)$ & $0.46(0-0.69)$ & $0(0-0.51)$ & $0.54(0.30-0.86)$ & $\mathrm{AE}$ & 6 & 6.77 & 0.34 \\
\hline & $\begin{array}{l}\text { L volume } \\
\qquad(95 \% \mathrm{Cls})\end{array}$ & $0.31(-0.08-0.62)$ & $0.08(-0.40-0.52)$ & $0.31(0-0.64)$ & $0(0-0)$ & $0.69(0.38-1)$ & $E$ & 6 & 6.75 & 0.34 \\
\hline & $\begin{array}{l}\text { R no. of tracts } \\
\quad(95 \% \mathrm{Cls})\end{array}$ & $0.49(0.12-0.74)$ & $0.49(0.04-0.78)$ & $0.05(0-0.70)$ & $0.45(0-0.68)$ & $0.50(0.27-0.78)$ & $(A+C) E$ & 6 & 12.1 & 0.06 \\
\hline & $\begin{array}{l}\text { Rvolume } \\
\qquad(95 \% \mathrm{Cls})\end{array}$ & $0.50(0.13-0.75)$ & $0.50(0.04-0.79)$ & $0(0-0.68)$ & $0.49(0-0.69)$ & $0.51(0.28-0.77)$ & $(A+C) E$ & 6 & 5.19 & 0.52 \\
\hline \multirow[t]{4}{*}{$\begin{array}{l}\text { Posterior indirect } \\
\text { segment }\end{array}$} & $\begin{array}{l}\text { L no. of tracts } \\
\quad(95 \% \text { Cls })\end{array}$ & $0.57(0.22-0.79)$ & $0.26(-0.28-0.68)$ & $0.48(0-0.75)$ & $0.07(0-0.66)$ & $0.46(0.24-0.78)$ & $(A+C) E$ & 6 & 3.27 & 0.77 \\
\hline & $\begin{array}{l}\text { L volume } \\
\qquad(95 \% \mathrm{Cls})\end{array}$ & $0.47(0.08-0.74)$ & $0.07(-0.52-0.43)$ & $0.39(0-0.67)$ & $0(0-0.45)$ & $0.61(0.32-0.99)$ & $E$ & 6 & 4.4 & 0.62 \\
\hline & $\begin{array}{l}\text { R no. of tracts } \\
\quad(95 \% \text { Cls })\end{array}$ & $0.35(-0.11-0.69)$ & $0.05(-0.48-0.56)$ & $0.28(0-0.58)$ & $0(0-0.54)$ & $0.72(0.41-1)$ & $E$ & 6 & 6.45 & 0.37 \\
\hline & $\begin{array}{l}\text { R volume } \\
\qquad(95 \% \mathrm{Cls})\end{array}$ & $0.45(0.04-0.73)$ & $0.23(-0.25-0.63)$ & $0.05(0-0.64)$ & $0.34(0-0.62)$ & $0.61(0.35-0.91)$ & $(A+C) E$ & 6 & 9.96 & 0.13 \\
\hline
\end{tabular}

In models indicated by $(A+C) E$, A and C individually are not significant, but combined are, and the associated DF, $\chi^{2}$, and $p$ values represent the fit of the full $A C E$ model. Note that all $p$ values are above 0.05 significance level, meaning that they are not significantly different from the saturated model, thus representing a good fit to our data.

milial effects $(\mathrm{A}+\mathrm{C})$ mostly influenced the variability of the long segments independent of hemisphere (59-71\%), whereas the variability of the anterior segments was to a similar degree determined by both familial and specific environmental factors (Table 1). The variability in the number of streamlines showed the right posterior segment to be under a higher degree of specific environmental effects (72\%) compared with all other segments (Fig. 4). Regarding the lateralization measures, the familial effects were statistically significant only for the long segment, whereas the variability of lateralization of anterior and posterior segments was influenced predominantly by the specific environment (Fig. 5).

Compared with the volumetric measures, FA and MD, which are likely to reflect architectural properties of the white matter fibers, are generally influenced more by genetic factors. In particular, the variability in MD measures of bilateral arcuate fasciculus is highly genetically driven. The genetic effects were significant for all the tracts and explained $54-78 \%$ of MD variability in bilateral long, anterior, and posterior segments (Fig. 5). Regarding the FA measures, genetic effects were also high and reached significance for the variability of the left long (62\%), right anterior $(66 \%)$, and left posterior segment $(67 \%)$. The genetic effects on the lateralization of FA and MD were high and reached significance only for the long segment (63\% and $61 \%$, respectively). For additional information on genetic and environmental sources of variance on the diffusion measures and their laterality indices, see Figure 5.

\section{Discussion}

We report here that, by early childhood, connections between frontal and temporal (long segment) and between frontal and parietal (anterior segment) regions are left and right lateralized, respectively, and remain lateralized throughout adolescence. In contrast, connections between temporal and parietal regions (posterior segment) are right lateralized in childhood, but be- come progressively bilateral during adolescence. Preliminary analysis of a twin sample suggested that lateralization of the arcuate fasciculus connections is a heterogeneous process that depends on the interplay between genetic and environment factors specific to each segment. Tracts that exhibit higher age effects (i.e., the right posterior segment) appear to be more influenced by specific environmental factors. Broadly, our findings support the view that adolescence remains a critical period for brain development (Giedd et al., 1999) and that there is a lower degree of genetic contribution to brain structures that mature later during brain development (Lohmann et al., 1999; Brun et al., 2009).

The temporoparietal cortical areas have been reported previously to be the slowest regions to mature among the perisylvian language network (Leroy et al., 2011). However, the specific finding that the posterior indirect segment that connects these temporoparietal regions exhibits a significant shift in lateralization from right to bilateral during adolescence has not been reported before. We observed that this lateralization shift (across ages 9-40 years) was associated with a reduction in the number of streamlines in the right hemisphere. This is consistent with the hypothesis that lateralization arises through axonal pruning and cell loss rather than an increase in axons and myelination (Galaburda et al., 1990). Age-related differences of the posterior segment may be related to its association with more complex functional requirements (Catani and Bambini, 2014). Temporoparietal regions are, for example, understood to be important for higher-order cognitive functions that include theory of mind (Apperly et al., 2004), control of intention to speak (Desmurget et al., 2009; Carota et al., 2010), semantic knowledge (Binder et al., 2009), reading (Thiebaut de Schotten et al., 2014), and higher pragmatic aspects of language (Catani and Bambini, 2014). Therefore, the posterior segment may act as a neural substrate for 


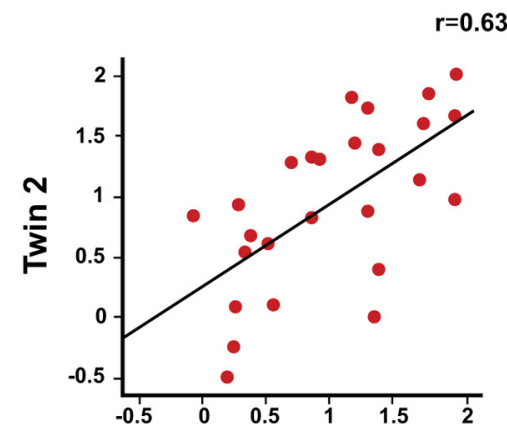

Twin 1
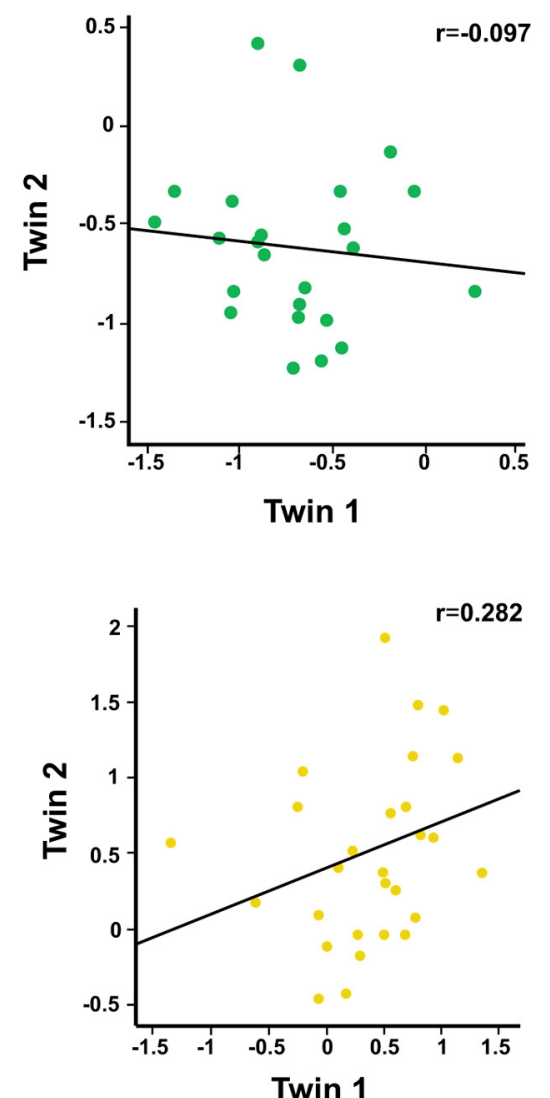

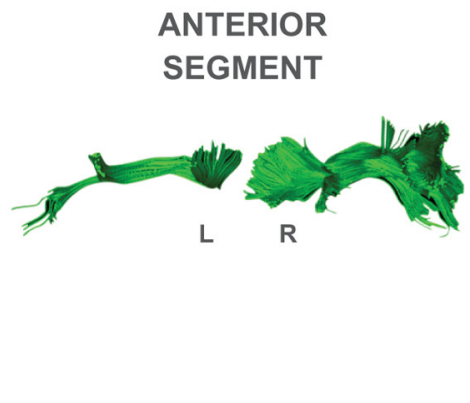

\section{POSTERIOR SEGMENT}

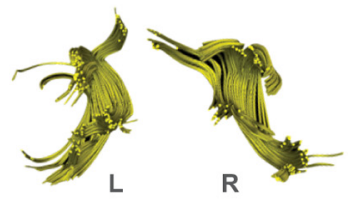

$\mathbf{R}$
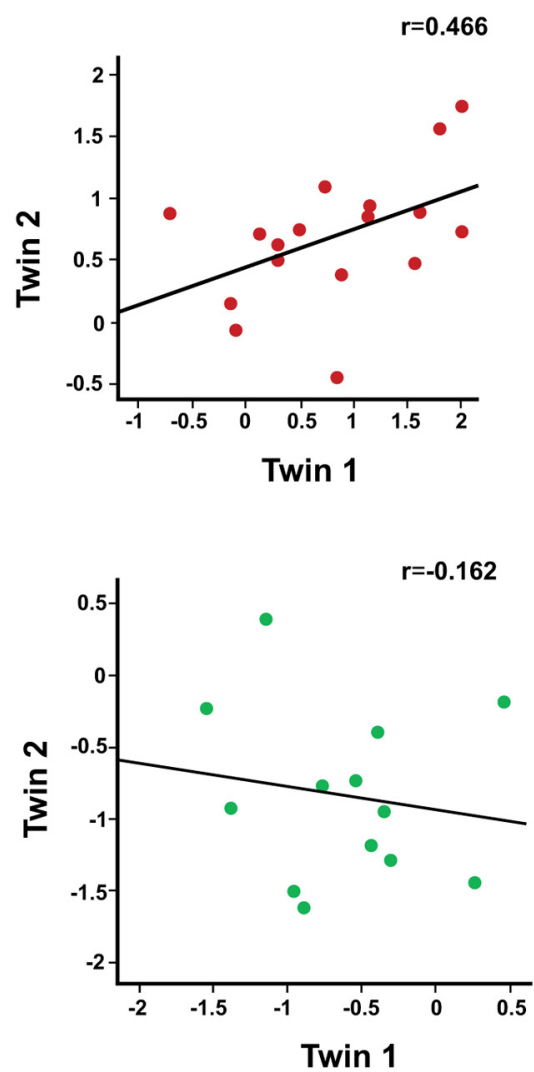

Twin 1

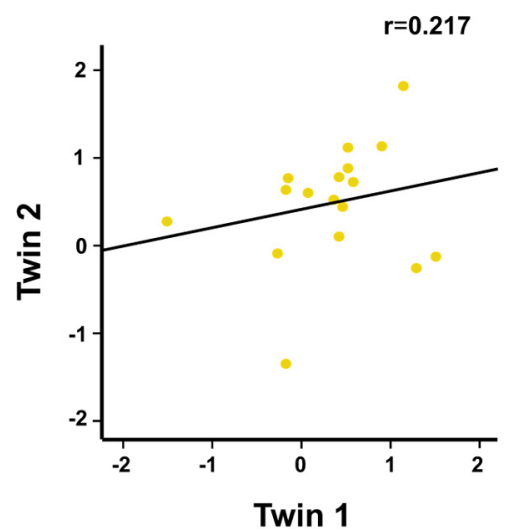

Figure 3. Plots of $\mathrm{LI}$ for each of the three arcuate segments in $\mathrm{MZ}$ versus $\mathrm{DZ}$ twins. ${ }^{* *} p<0.001$.

higher-order mental processes that involve both language and social cognition (Catani and Bambini, 2014). This is consistent with the hypothesis that the long direct segment supports early stages of language acquisition, whereas the indirect pathways become more relevant for complex processing during later stages of language development (Perani et al., 2011). Further, age effects on the posterior segment may partially explain children's initial stronger reliance on the right hemisphere, reflected in a more rightward functional lateralization during language processing compared with adults (Brauer and Friederici, 2007). In addition to its implications regarding language development, the finding that the structural variability of the posterior segment is particularly influenced by specific environmental factors may have significant clinical implications (Forkel et al., 2014).
Individual differences in the structure of the arcuate fasciculus are associated with variability in specific cognitive functions and vulnerability to neuropsychiatric disorders such as autism (Fletcher et al., 2010; Billeci et al., 2012; Ameis and Catani, 2015) and schizophrenia (Catani et al., 2011). We reported previously that schizophrenia is associated with abnormalities in pathways that connect selectively to posterior temporal regions, including the posterior segment of the arcuate fasciculus (Catani et al., 2011). Previous studies suggested that later-developing white matter structures are more vulnerable to environmental stressors (Kochunov et al., 2012; Rosenzweig et al., 2012), probably due to the effects of subtle metabolic and oxidative damage on latedeveloping myelin (Bartzokis, 2011). During adolescence, the posterior segment may therefore represent a specific target for 


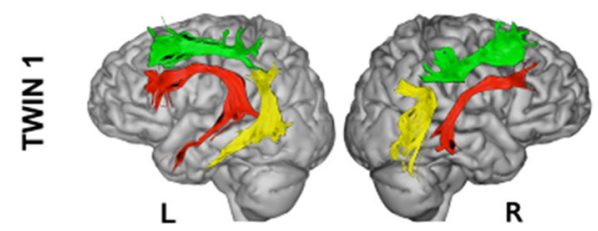

MZ
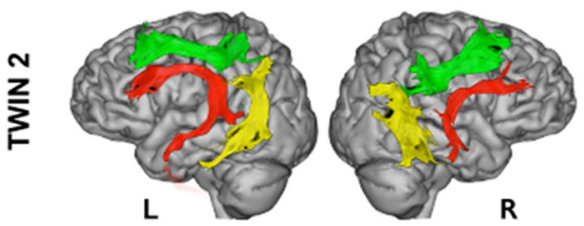

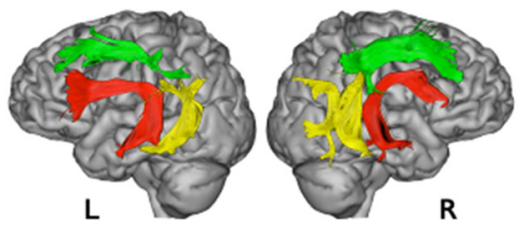

DZ
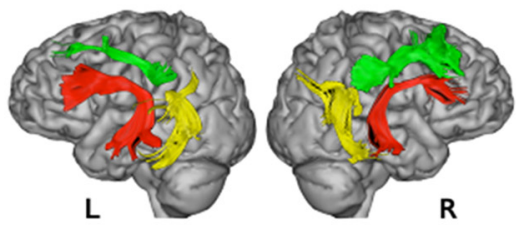

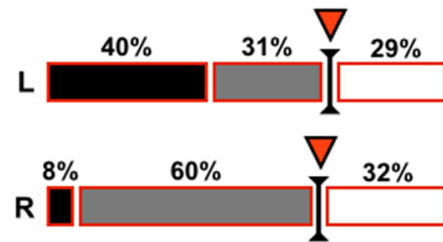

genetic
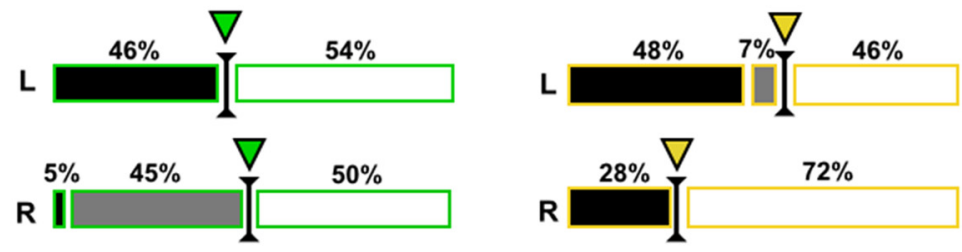

specific environment

Figure 4. The relative contribution (in percentages) of genetic, shared environmental, and specific environmental factors on the variability of the number of streamlines of the long, anterior and posterior segments in the left $(\mathrm{L})$ and right $(\mathrm{R})$ hemisphere. The border between familial (genetic and shared environmental) and specific environmental influences is shown with a triangle. The example of the virtual dissection of three perisylvian segments in one MZ and DZ twin pair is shown as a visual reference (segments are shown as detached from one another for clearer visual inspection).

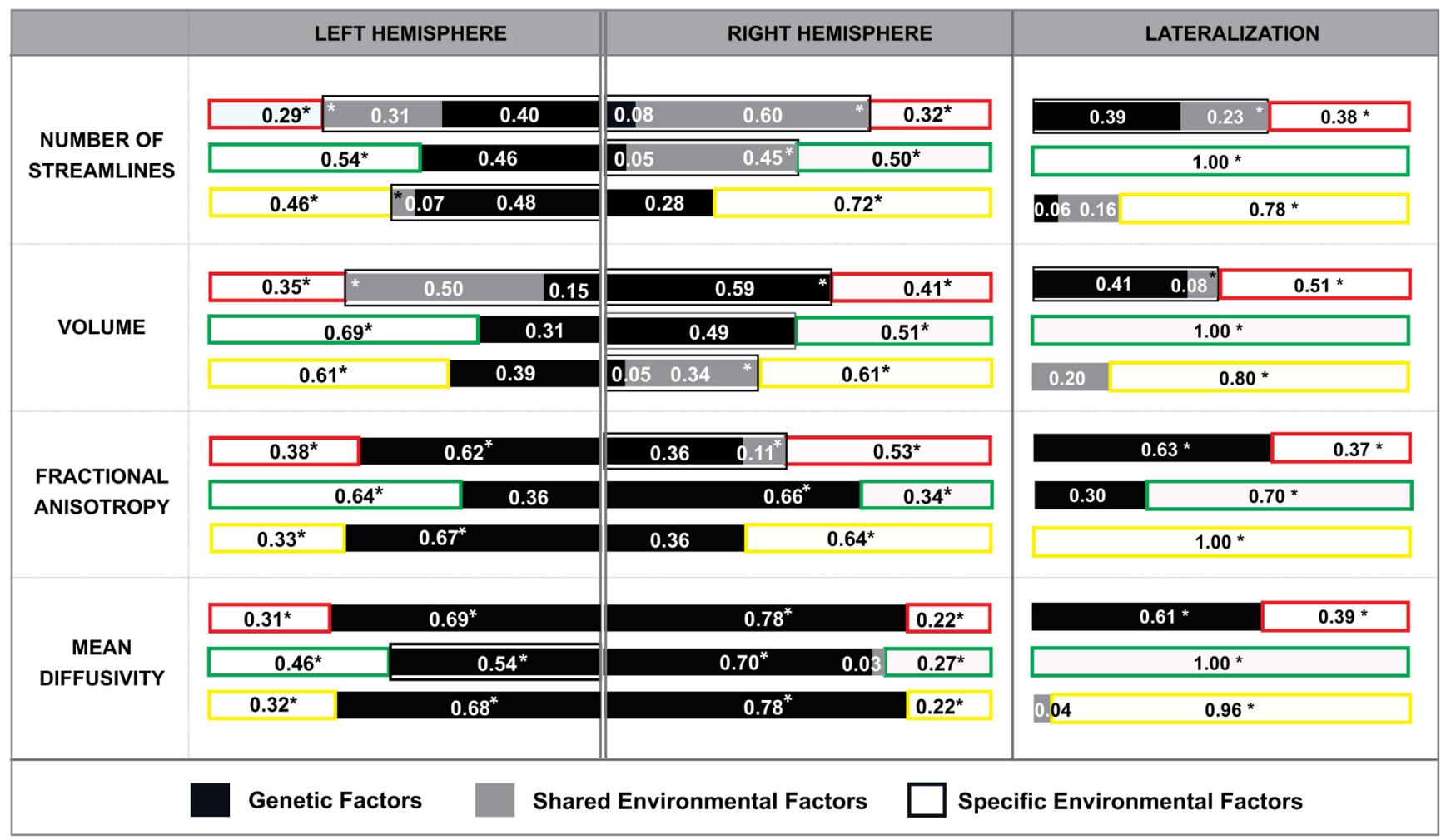

Figure 5. The relative proportion of $A, C$, and E on the variability of the number of streamlines, volume, $F A$, mean diffusivity, and their Lls for the long (in red), anterior (in green), and posterior (in yellow) segments. A box was drawn around A and C values in cases in which A and C were not significant individually, but reached significance when combined. * ${ }^{*}$ Significant contribution at $p<0.05$.

environmental "toxins" such as cannabis in the etiology of schizophrenia (Malone et al., 2010). Future studies are now required to test which toxins could specifically affect the posterior segment. Similarly, future studies are needed to ascertain whether therapies such as deep transcranial magnetic stimulation applied over the right posterior segment might have a protective role in high-risk/prodromal individuals (Rosenberg et al., 2012). In summary, furthering our understanding of the age effects and 
heritability patterns of specific perisylvian language pathways may ultimately have real translational implications for clinical practice.

Last, our study observed an age-related decrease in MD in bilateral indirect segments (anterior and posterior) and the left long segment. This MD decrease across age is a consistent finding in DTI studies (Schmithorst et al., 2002; Barnea-Goraly et al., 2005; Bonekamp et al., 2007; Dubois et al., 2006). MD is the overall magnitude of water diffusion and is a sensitive indicator of maturational changes in brain tissue. A decrease in MD would reflect a decrease in brain water content and an increase in axonal membrane density (Neil et al., 2002). Conversely, we found no age-related differences in FA, which is consistent with Eluvathingal et al. (2007), but not other studies. Overall, these findings suggest that MD measures could be more sensitive to age than FA measures (Schmithorst et al., 2002; Schneider et al., 2004; Barnea-Goraly et al., 2005). Our twin analysis in adults showed that MD values are highly heritable for all three arcuate segments in both hemispheres (genetic factors influence $54-78 \%$ of variability), so it is likely that genes play an important role in the observed decrease of MD across age.

Although our study had a number of strengths, it also has several limitations that need to be considered when interpreting the findings. First, there are the technical limitations of DTI-MRI tractography such as the inability to solve crossing or "kissing" of fibers, leading to possible presence of false positives and false negatives (Catani et al., 2012a; Dell'Acqua and Catani, 2012). However, all three segments of the arcuate fasciculus were inspected visually to ensure that they conformed to known anatomical trajectories. Second, our findings of the age effects on the arcuate segments are based on a cross-sectional study design. Therefore, the finding that the volume of the right posterior segment decreases with age should be taken with caution and replicated with longitudinal data collection and inclusion of the accompanying cognitive changes along development. It is also possible that the decrease in the volume of the right posterior segment reflects a limitation of the DTI technique and instead reflects surrounding white matter, with the crossing fibers growing larger over time and "hiding" this component from segmentation. Furthermore, standard limitations of the classical twin study design should be taken into account. These include violating assumptions such as equal environments between MZ and DZ twins (however, research shows that this assumption is generally valid; Plomin et al., 2001); presence of ascertainment bias; problems with significant gene-environment correlations and interactions; lack of follow-up of the phenotypes over time; and environmental noise (Boomsma et al., 2002). In addition, there is the question of whether the results of twin studies can be transposed directly to nontwin population because twins are more likely than singletons to experience adverse prenatal and perinatal events that may affect brain development (Norwitz et al., 2005). Further, twins are slower in developing language functions compared with singletons, but this delay diminishes during childhood (Rutter and Redshaw, 1991) and studies report that there are no significant differences in the brain structures between twins and singletons in healthy pediatric (Ordaz et al., 2010) and adult populations (Hulshoff Pol et al., 2002). Nevertheless, our findings are valid only for the adult population because heritability changes with age. Indeed, regions associated with complex cognitive processes such as language are more heritable in adolescents than in children (Lenroot et al., 2009). For the standards of quantita- tive genetics, our twin study was further limited by sample size, leading to the confidence intervals of heritability estimates to be wide. A large sample is necessary to detect shared environmental (C) effects (Posthuma and Boomsma, 2000). However, the reduction in power was overcome by reporting $\mathrm{C}$ and $\mathrm{A}$ (genetic) effects in combination when they were statistically significant together and expressing them as "familial effects” (Wright et al., 2002). Finally, our analyses of agerelated changes and heritability were performed in two separate groups that had different mean age. Future studies are needed to determine the exact contribution of genetic and environmental factors to maturational changes occurring at specific age periods in the same sample.

In conclusion, our findings suggest that, during childhood and adolescence, the timing of lateralization within the perisylvian language network varies for different segments, with the posterior indirect segment being the last one to complete its lateralization process. Further, analysis of the twin population suggests that, relative to the other tracts, the posterior segment is more influenced by specific environmental effects. These findings have potential implications for our current understanding of language development and the etiology of psychiatric conditions that affect the perisylvian networks.

\section{References}

Ameis SH, Catani M (2015) Altered white matter connectivity as a neural substrate for social impairment in Autism Spectrum Disorder. Cortex 62:158-181. CrossRef Medline

Apperly IA, Samson D, Chiavarino C, Humphreys GW (2004) Frontal and temporo-parietal lobe contributions to theory of mind: neuropsychological evidence from a false-belief task with reduced language and executive demands. J Cogn Neurosci 16:1773-1784. CrossRef Medline

Barnea-Goraly N, Menon V, Eckert M, Tamm L, Bammer R, Karchemskiy A, Dant CC, Reiss AL (2005) White matter development during childhood and adolescence: a cross-sectional diffusion tensor imaging study. Cereb Cortex 15:1848-1854. CrossRef Medline

Bartzokis G (2011) Neuroglialpharmacology: white matter pathophysiologies and pathophysiologies and psychiatric treatments. Front Biosci (Landmark Ed) 16:2695-2733. CrossRef Medline

Billeci L, Calderoni S, Tosetti M, Catani M, Muratori F (2012) White matter connectivity in children with autism spectrum disorders: a tract-based spatial statistics study. BMC Neurol 12:1-16. CrossRef Medline

Binder JR, Desai RH, Graves WW, Conant LL (2009) Where is the semantic system? A critical review and meta-analysis of 120 functional neuroimaging studies. Cereb Cortex 19:2767-2796. CrossRef Medline

Boker S, Neale M, Maes H, Wilde M, Spiegel M, Brick T, Spies J, Estabrook R, Kenny S, Bates T, Mehta P, Fox J (2011) OpenMx: an open source extended structural equation modeling framework. Psychometrika 76:306317. CrossRef Medline

Bonekamp D, Nagae LM, Degaonkar M, Matson M, Abdalla WM, Barker PB, Mori S, Horská A (2007) Diffusion tensor imaging in children and adolescents: reproducibility, hemispheric, and age-related differences. Neuroimage 34:733-742. Medline

Boomsma D, Busjahn A, Peltonen L (2002) Classical twins studies and beyond. Nat Rev Genet 3:872-882. CrossRef Medline

Brauer J, Friederici AD (2007) Functional neural networks of semantic and syntactic processes in the developing brain. J Cogn Neurosci 19:1609_ 1623. CrossRef Medline

Brouwer RM, Mandl RC, Peper JS, van Baal GC, Kahn RS, Boomsma DI, Hulshoff Pol HE (2010) Heritability of DTI and MTR in nine-year old children. Neuroimage 53:1085-1092. CrossRef Medline

Brun C, Leporé N, Pennec X, Lee AD, Barysheva M, Madsen SK, Avedissian C, Chou YY, de Zubicaray GI, McMahon KL, Wright MJ, Toga AW, Thompson PM (2009) Mapping the regional influence of genetics on brain structure variability - a tensor-based morphometry study. Neuroimage 48:37-49. CrossRef Medline

Carota F, Posada A, Harquel S, Delpuech C, Bertrand O, Sirigu A (2010) Neural dynamics of the intention to speak. Cereb Cortex 20:1891-1897. CrossRef Medline 
Catani M, Howard RJ, Pajevic S, Jones DK (2002) Virtual in vivo interactive dissection of white matter fasciculi in the human brain. Neuroimage 17: 77-94. CrossRef Medline

Catani M, Piccirilli M, Cherubini A, Tarducci R, Sciarma T, Gobbi G, Pelliccioli G, Petrillo SM, Senin U, Mecocci P (2003) Axonal injury within language network in primary progressive aphasia. Ann Neurol 53:242247. CrossRef Medline

Catani M, Thiebaut de Schotten M (2008) A diffusion tensor imaging tractography atlas for in vivo dissections. Cortex 44:1105-1132. CrossRef Medline

Catani M, Mesulam MM (2008) The arcuate fasciculus and the disconnection theme in language and aphasia: history and current state. Cortex 44:953961. CrossRef Medline

Catani M, Bode Istvan, Dell'Acqua F (2012a) Comment on "The Geometric Structure of the Brain Fiber Pathways". Science 337:1605. Medline

Catani M, Dell'acqua F, Bizzi A, Forkel SJ, Williams SC, Simmons A, Murphy DG, Thiebaut de Schotten M (2012b) Beyond cortical localisation in clinico-anatomical correlation. Cortex 48:1262-1287. CrossRef Medline

Catani M, Bambini V (2014) A model for social communication and language evolution and development (SCALED). Curr Opin Neurobiol 28: 165-171. CrossRef Medline

Catani M, Jones DK, ffytche DH (2005) Perisylvian language networks of the human brain. Ann Neurol 57:8-16. CrossRef Medline

Catani M, Allin MP, Husain M, Pugliese L, Mesulam MM, Murray RM, Jones DK (2007) Symmetries in human brain language pathways correlate with verbal recall. Proc Natl Acad Sci U S A 104:17163-17168. CrossRef Medline

Catani M, Craig MC, Forkel SJ, Kanaan R, Picchioni M, Toulopoulou T, Shergill S, Williams S, Murphy DG, McGuire P (2011) Altered integrity of perisylvian language pathways in schizophrenia: relationship to auditory hallucinations. Biol Psychiatry 70:1143-1150. CrossRef Medline

Chiang MC, Barysheva M, Shattuck DW, Lee AD, Madsen SK, Avedissian C, Klunder AD, Toga AW, McMahon KL, de Zubicaray GI, Wright MJ, Srivastava A, Balov N, Thompson PM (2009) Genetics of brain fiber architecture and intellectual performance. J Neurosci 29:2212-2224. CrossRef Medline

Dell'Acqua F, Catani M (2012) Structural human brain networks. Curr Opin Neurol 25:375-383. Medline

Desmurget M, Reilly KT, Richard N, Szathmari A, Mottolese C, Sirigu A (2009) Movement intention after parietal cortex stimulation in humans. Science 324:811-813. CrossRef Medline

Dubois J, Hertz-Pannier L, Dehaene-Lambertz G, Cointepas Y, Le Bihan D (2006) Assessment of the early organization and maturation of infants' cerebral white matter fiber bundles: a feasibility study using quantitative diffusion tensor imaging and tractography. Neuroimage 30:1121-1132. CrossRef Medline

Dubois J, Hertz-Pannier L, Cachia A, Mangin JF, Le Bihan D, DehaeneLambertz G (2009) Structural asymmetries in the infant language and sensori-motor networks. Cereb Cortex 19:414-423. CrossRef Medline

Eluvathingal TJ, Hasan KM, Kramer L, Fletcher JM, Ewing-Cobbs L (2007) Quantitative diffusion tensor tractography of association and projection fibers in normally developing children and adolescents. Cereb Cortex 17:2760-2768. CrossRef Medline

Fletcher PT, Whitaker RT, Tao R, DuBray MB, Froehlich A, Ravichandran C, Alexander AL, Bigler ED, Lange N, Lainhart JE (2010) Microstructural connectivity of the arcuate fasciculus in adolescents with high functioning autism. Neuroimage 51:1117-1125. CrossRef Medline

Forkel SJ, Thiebaut de Schotten M, Dell'Acqua F, Kalra L, Murphy DG, Williams SC, Catani M (2014) Anatomical predictors of aphasia recovery: a tractography study of bilateral perisylvian language networks. Brain 137: 2027-2039. CrossRef Medline

Galaburda AM, Rosen GD, Sherman GF (1990) Individual variability in cortical organization: its relationship to brain laterality and implications to function. Neuropsychologia 28:529-546. CrossRef Medline

Giedd JN, Blumenthal J, Jeffries NO, Castellanos FX, Liu H, Zijdenbos A, Paus T, Evans AC, Rapoport JL (1999) Brain development during childhood and adolescence: a longitudinal MRI study. Nat Neurosci 2:861-863. CrossRef Medline

Hulshoff Pol HE, Posthuma D, Baaré WFC, De Geus EJC, Schnack HG, van Haren NEM, van Oel CJ, Kahn RS, Boomsma DI (2002) Twin-singleton differences in brain structure using structural equation modelling. Brain 125(Pt 2):384-390.
Jones DK, Williams SC, Gasston D, Horsfield MA, Simmons A, Howard R (2002) Isotropic resolution diffusion tensor imaging with whole brain acquisition in a clinically acceptable time. Hum Brain Mapp 15:216-230. CrossRef Medline

Joshi AA, Leporé N, Joshi SH, Lee AD, Barysheva M, Stein JL, McMahon KL, Johnson K, de Zubicaray GI, Martin NG, Wright MJ, Toga AW, Thompson PM (2011) The contribution of genes to cortical thickness and volume. Neuroreport 22:101-105. CrossRef Medline

Kochunov P, Glahn DC, Lancaster JL, Winkler AM, Smith S, Thompson PM, Almasy L, Duggirala R, Fox PT, Blangero J (2010) Genetics of microstructure of cerebral white matter using diffusion tensor imaging. Neuroimage 53:1109-1116. CrossRef Medline

Kochunov P, Williamson DE, Lancaster J, Fox P, Cornell J, Blangero J, Glahn DC (2012) Fractional anisotropy of white matter diffusion in cerebral white matter across the lifespan. Neurobiol Aging 33:9-20. CrossRef Medline

Lebel C, Beaulieu C (2009) Lateralization of the arcuate fasciculus from childhood to adulthood and its relation to cognitive abilities in children. Hum Brain Mapp 30:3563-3573. CrossRef Medline

Leemans A, Jeurissen B, Sijbers J, Jones DK (2009) ExploreDTI: a graphical toolbox for processing, analysing, and visualizing diffusion MR data. Proceedings of the International Society for Magnetic Resonance in Medicine 17:3536.

Lenroot RK, Schmitt JE, Ordaz SJ, Wallace GL, Neale MC, Lerch JP, Kendler KS, Evans AC, Giedd JN (2009) Differences in genetic and environmental influences on the human cerebral cortex associated with development during childhood and adolescence. Hum Brain Mapp 30:163-174. CrossRef Medline

Leroy F, Glasel H, Dubois J, Hertz-Pannier L, Thirion B, Mangin JF, DehaeneLambertz G (2011) Early maturation of the linguistic dorsal pathway in human infants. J Neurosci 31:1500-1506. CrossRef Medline

Lohmann G, von Cramon DY, Steinmetz H (1999) Sulcal variability of twins. Cereb Cortex 9:754-763. CrossRef Medline

López-Barroso D, Catani M, Ripollés P, Dell'Acqua F, Rodríguez-Fornells A, de Diego-Balaguer R (2013) Word learning is mediated by the left arcuate fasciculus. Proc Natl Acad U S A 110:13168-13173. CrossRef Medline

Malone DT, Hill MN, Rubino T (2010) Adolescent cannabis use and psychosis: epidemiology and neurodevelopmental models. Br J Pharmacol 160:511-522. CrossRef Medline

Neale MC, Maes HHM (2002) Methodology for genetic studies of twins and families. Dordrecht, Netherlands: Kluwer.

Neale MC, Eaves LJ, Kendler KS (1994) The power of the classical twin study to resolve variation in threshold traits. Behav Genet 24:239-258. CrossRef Medline

Neil JJ, Miller J, Mukherjee P, Huppi PS (2002) Diffusion tensor imaging of normal and injured developing human brain-a technical review. NMR Biomed 15(7-8):543-552.

Norwitz ER, Edusa V, Park JS (2005) Maternal physiology and complications of multiple pregnancy. Semin Perinatol 29:338-348. CrossRef Medline

Oldfield RC (1971) The assessment and analysis of handedness: the Edinburgh inventory. Neuropsychologia 9:97-113. CrossRef Medline

Ordaz SJ, Lenroot RK, Wallace GL, Clasen LS, Blumenthal JD, Schmitt JE, Giedd JN (2010) Are there differences in brain morphometry between twins and unrelated singletons? A pediatric MRI study. Genes Brain Behav 9:288-295. CrossRef Medline

Paus T, Zijdenbos A, Worsley K, Collins DL, Blumenthal J, Giedd JN, Rapoport JL, Evans AC (1999) Structural maturation of neural pathways in children and adolescents: in vivo study. Science 283:1908-1911. CrossRef Medline

Perani D1, Saccuman MC, Scifo P, Anwander A, Spada D, Baldoli C, Poloniato A, Lohmann G, Friederici AD (2011) Neural language networks at birth. Proc Natl Acad Sci U S A 108:16056-16061. CrossRef Medline

Plomin R, DeFries JC, McClearn GE, McGuffin P (2001) Behavioral genetics, Ed 4. New York: Worth.

Posthuma D, Boomsma DI (2000) A note on the statistical power in extended twin designs. Behav Genet 30:147-158. CrossRef Medline

Rosenberg O, Gersner R, Klein LD, Kotler M, Zangen A, Dannon P (2012) Deep transcranial magnetic stimulation add-on for the treatment of auditory hallucinations: a double-blind study. Ann Gen Psychiatry 11:13. CrossRef Medline

Rosenzweig I, Vukadinovic Z, Turner AJ, Catani M (2012) Neuroconnec- 
tivity and valproic acid: the myelin hypothesis. Neurosci Biobehav Rev 36:1848-1856. CrossRef Medline

Rutter M, Redshaw J (1991) Annotation: Growing up as a twin: Twinsingleton differences in psychological development. J Child Psychol Psychiatry 32:885-895. CrossRef Medline

Schmahmann JD, Pandya DN (2006) Fiber pathways of the brain. New York: OUP.

Schmithorst VJ, Wilke M, Dardzinski BJ, Holland SK (2002) Correlation of white matter diffusivity and anisotropy with age during childhood and adolescence: across-sectional diffusion-tensor MR imaging study. Radiology 222:212-218. CrossRef Medline

Schneider JF, Il'yasov KA, Hennig J, Martin E (2004) Fast quantitative diffusion-tensor imaging of cerebral white matter from the neonatal period to adolescence. Neuroradiology 46:258-266. CrossRef Medline

Stromswold K (2001) The heritability of language: a review and meta- analysis of twin, adoption and linkage studies. Language 77:647-723. CrossRef

Thiebaut de Schotten M, Dell'Acqua F, Forkel SJ, Simmons A, Vergani F, Murphy DG, Catani M (2011) A lateralized brain network for visuospatial attention. Nat Neurosci 14:1245-1246. CrossRef Medline

Thiebaut de Schotten M, Cohen L, Amemiya E, Braga LW, Dehaene S (2014) Learning to read improves the structure of the arcuate fasciculus. Cereb Cortex 24:989-995. CrossRef Medline

Thompson PM, Cannon TD, Narr KL, van Erp T, Poutanen VP, Huttunen M, Lönnqvist J, Standertskjöld-Nordenstam CG, Kaprio J, Khaledy M, Dail R, Zoumalan CI, Toga AW (2001) Genetic influences on brain structure. Nat Neurosci 4:1253-1258. Medline

Wright IC, Sham P, Murray RM, Weinberger DR, Bullmore ET (2002) Genetic contributions to regional variability in human brain structure: methods and preliminary results. Neuroimage 17:256-271. CrossRef Medline 